\title{
Correction to: Rapid establishment of a national surveillance of COVID-19 hospitalizations in Belgium
}

Nina Van Goethem ${ }^{1,2^{*}}$, Aline Vilain ${ }^{1}$, Chloé Wyndham-Thomas', Jessika Deblonde ${ }^{1}$, Nathalie Bossuyt', Tinne Lernout ${ }^{1}$, Javiera Rebolledo Gonzalez ${ }^{1}$, Sophie Quoilin ${ }^{1}$, Vincent Melis ${ }^{3}$ and Dominique Van Beckhoven ${ }^{1}$

\section{Correction to: Arch Public Health 78, 121 (2020) https://doi.org/10.1186/s13690-020-00505-z}

Following publication of the original article [1], the author reported an error in the affiliations:

The original first affiliation was

1. Public health and genome, Scientific Directorate of Epidemiology and public health, Sciensano, J. Wytsmanstraat 14, 1050 Brussels, Belgium

The correct affiliation has been provided in this Correction.

1. Scientific Directorate of Epidemiology and public health, Sciensano, J. Wytsmanstraat 14, 1050 Brussels, Belgium

The original article [1] has been updated.

\section{Author details}

${ }^{1}$ Scientific Directorate of Epidemiology and Public Health, Sciensano, J.

Wytsmanstraat 14, 1050 Brussels, Belgium. ${ }^{2}$ Department of Epidemiology and Biostatistics, Institut de recherche expérimentale et clinique, Faculty of Public Health, Université catholique de Louvain, Clos Chapelle-aux-champs 30, 1200 Woluwe-Saint-Lambert, Belgium. ${ }^{3}$ Directorate Healthcare, Federal Public Service (FPS) Health, Food Chain Safety and Environment, Brussels, Belgium.
Published online: 18 August 2021

\section{Reference}

1. Van Goethem N, Vilain A, Wyndham-Thomas C, et al. Rapid establishment of a national surveillance of COVID-19 hospitalizations in Belgium. Arch Public Health. 2020;78:121. https://doi.org/10.1186/s13690-020-00505-z.

The original article can be found online at https://doi.org/10.1186/s13690020-00505-z.

* Correspondence: Nina.VanGoethem@sciensano.be

${ }^{1}$ Scientific Directorate of Epidemiology and Public Health, Sciensano, J. Wytsmanstraat 14, 1050 Brussels, Belgium

${ }^{2}$ Department of Epidemiology and Biostatistics, Institut de recherche expérimentale et clinique, Faculty of Public Health, Université catholique de Louvain, Clos Chapelle-aux-champs 30, 1200 Woluwe-Saint-Lambert, Belgium

Full list of author information is available at the end of the article

C C The Author(s). 2021 Open Access This article is licensed under a Creative Commons Attribution 4.0 International License, which permits use, sharing, adaptation, distribution and reproduction in any medium or format, as long as you give appropriate credit to the original author(s) and the source, provide a link to the Creative Commons licence, and indicate if changes were made. The images or other third party material in this article are included in the article's Creative Commons licence, unless indicated otherwise in a credit line to the material. If material is not included in the article's Creative Commons licence and your intended use is not permitted by statutory regulation or exceeds the permitted use, you will need to obtain permission directly from the copyright holder. To view a copy of this licence, visit http://creativecommons.org/licenses/by/4.0/ The Creative Commons Public Domain Dedication waiver (http://creativecommons.org/publicdomain/zero/1.0/) applies to the data made available in this article, unless otherwise stated in a credit line to the data. 